\title{
Modelowanie przeplywu dyspersji cementowej jako cieczy nieliniowo plastycznie lepkiej
}

\author{
Jerzy Szerafin ${ }^{1}$, Pawel Zaprawa ${ }^{2}$ \\ ${ }^{1}$ Katedra Konstrukcji Budowlanych, Wydziat Budownictwa i Architektury, Politechnika Lubelska \\ e-mail: j.szerafin@pollub.pl \\ ${ }^{2}$ Instytut Technologicznych Systemów Informacyjnych, Wydział Mechaniczny, Politechnika Lubelska \\ e-mail:p.zaprawa@pollub.pl
}

Streszczenie: $\mathrm{W}$ artykule zaprezentowano rozwiązanie analityczne przepływu dyspersji cementowej w prostoliniowych przewodach cylindrycznych, jako cieczy nieliniowo plastycznie lepkiej na tle innych modeli reologicznych. Przeprowadzone obliczenia rozkładu ciśnienia tłocznego oraz zasięgu przepływu wskazują na konieczność uwzględniania oporów natury tarciowej w analizie przepływu mieszanki cementowej.

Słowa kluczowe: dyspersja cementowa, przepływ, modelowanie.

\section{Wprowadzenie}

Problematyka modelowania przepływu dyspersji cementowych ma istotne praktyczne znaczenie $w$ wielu inżynierskich zastosowaniach, takich jak naprawy iniekcyjne elementów konstrukcyjnych, iniekcyjne wzmacnianie gruntów, czy wypełnianie kanałów w elementach kablobetonowych. Prace te należą do trudnych, między innymi ze względu na zasadniczy brak możliwości poprawienia źle przeprowadzonej próby. Dlatego prace te wymagają już na etapie ich projektowania dobrego rozeznania możliwych do osiągnięcia efektów. W tym celu od dawna podejmowane są próby ujęcia zagadnienia przepływu cieczy dyspersyjnej, zarówno analityczne (przykładowo: [1,2]), jak i z wykorzystaniem metod numerycznych $[3,4]$. Aktualnie zarówno jedne jak i drugie dalekie są jeszcze od doskonałości, jakkolwiek widoczny jest stały postęp w tej dziedzinie.

\section{Modele reologiczne dyspersji cementowej}

Podstawowym zagadnieniem w modelowaniu przepływu jest przyjęcie prawidłowego modelu reologicznego zaczynu cementowego, uwzględniającego jego dyspersyjny charakter. W skondensowanej zawiesinie poszczególne ziarna cementu oddziaływują na siebie nawzajem w punktach styków, gdzie pojawiają się siły elektrostatyczne Coulomba oraz siły van der Waalsa o charakterze przyciągającym. Wskutek oddziaływań elektrostatycznych na powierzchniach ziaren cementu tworzy się tzw. elektryczna warstwa podwójna, odpowiedzialna $\mathrm{z}$ kolei za powstawanie sił o charakterze odpychającym. W wyniku interakcji tych oddziaływań, a także pojawiających się sił kapilarnych wytwarza się stan równowagi, przejawiający się powstaniem struktury o pewnej wytrzymałości, określanej jako granica ścinania (płynności) $\tau_{0}$. Po jej przekroczeniu dyspersja ulega odkształceniom postaciowym charakterystycznym dla płynów. Towarzyszą tym odkształceniom opory przepływu, których miarą jest lepkość plastyczna $\eta_{p l}$. 
Charakter reologiczny zawiesiny cementowej jest złożony, i jak wskazują liczne wyniki badań - dość niejednoznaczny. Na podstawie obszernych danych dostępnych w literaturze, w tym w monografiach polskojęzycznych [5, 6] można przyjąć przedstawiony na Rys. 1 plastycznie lepki model przepływu z wyraźną nieliniowością, obserwowaną zwłaszcza w przypadku zaczynów o większych zawartościach fazy stałej. Granica płynności $\tau_{0}$ odczytywana jest jako punkt przecięcia krzywej płynięcia z osią naprężeń, natomiast lepkość plastyczna jest tangensem kąta nachylenia prostej (lub odpowiednio: stycznej do krzywej w danym punkcie) do osi poziomej. Warto zauważyć, że wyznaczone w ten sposób parametry reologiczne mogą przyjmować różne wartości, w zależności od przyjętego modelu reologicznego.

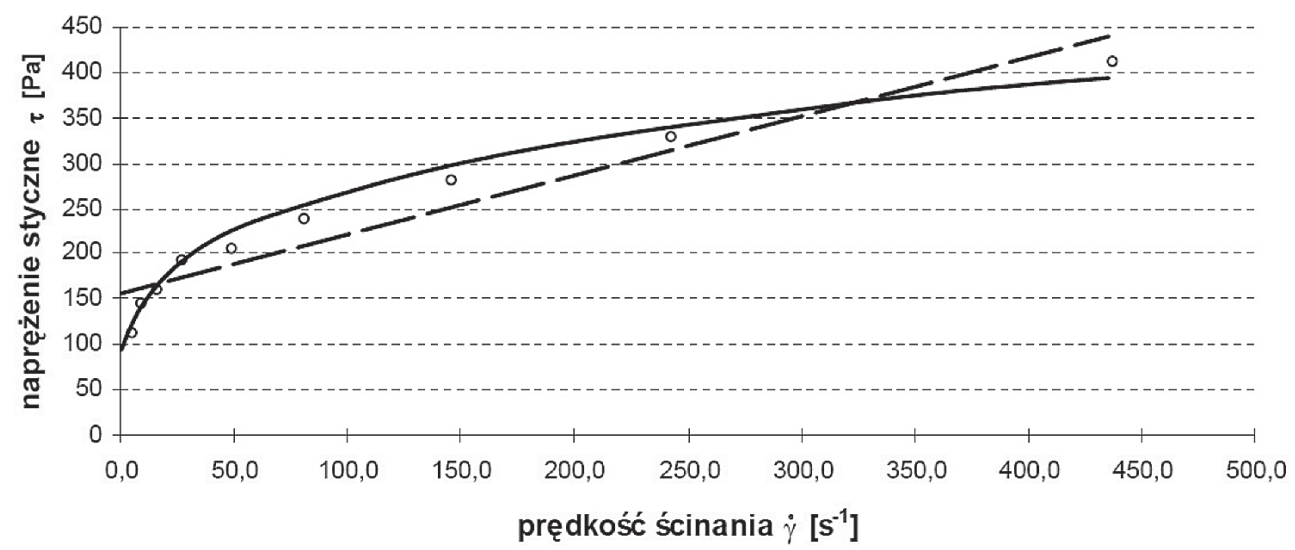

Rys. 1. Charakter płynięcia zaczynu cementowego na przykładzie wyników badań własnych. Linia przerywana i ciągła oznacza odpowiednio: aproksymację liniową i nieliniową wyników badań

Model liniowy opisany jest równaniem reologicznym Binghama:

$$
\tau=\tau_{0}+\eta_{p l} \cdot \dot{\gamma}
$$

zawierającym oba podstawowe parametry reologiczne. Ze względu na swoją prostotę oraz dobrą dokładność jest on chętnie przyjmowany do opisu przepływu zaczynów cementowych. Uwzględnienie nieliniowości krzywej płynięcia wymaga wprowadzenia dodatkowego parametru, opisującego zmienność lepkości przy wzroście prędkości ścinania. W niniejszej pracy przyjęto do dyskusji model wykładniczy, w postaci równania:

$$
\tau=\tau_{0}+\eta_{p l} \cdot \dot{\gamma}^{n}
$$

\section{Modelowanie oporów przepływu natury tarciowej}

W przypadku cieczy niedyspersyjnych, o oporach płynięcia stanowi (dla płynów nienewtonowskich) granica ścinania $\tau_{0}$ oraz lepkość $\eta$. Opis ten odzwierciedla występowanie oporów odpowiednio natury spójnościowej $\tau_{c}$ i lepkościowej $\tau_{\eta}$. Autor pracy [7] zauważa, że ciecze dyspersyjne cechują się ponadto występowaniem oporów natury tarciowej $\tau_{f}$, 
występujących na stykach wzajemnie przemieszczających się względem siebie cząstek stałych. Sumaryczny opór ścinania można więc zapisać w postaci:

$$
\tau=\tau_{c}+\tau_{f}+\tau_{\eta}
$$

W zaczynie cementowym, na ziarnach cząstek stałych tworzy się warstewka zaadsorbowanej wody wykazującej właściwości sprężyste wskutek panującego w niej podwyższonego ciśnienia. Przyjęto w dalszych rozważaniach mechanizm powstawania oporów tarciowych w stykach ziaren cementu w otoczkach wodnych, spłaszczanych wskutek panującego ciśnienia łłocznego, jak to zilustrowano na Rys. 2.
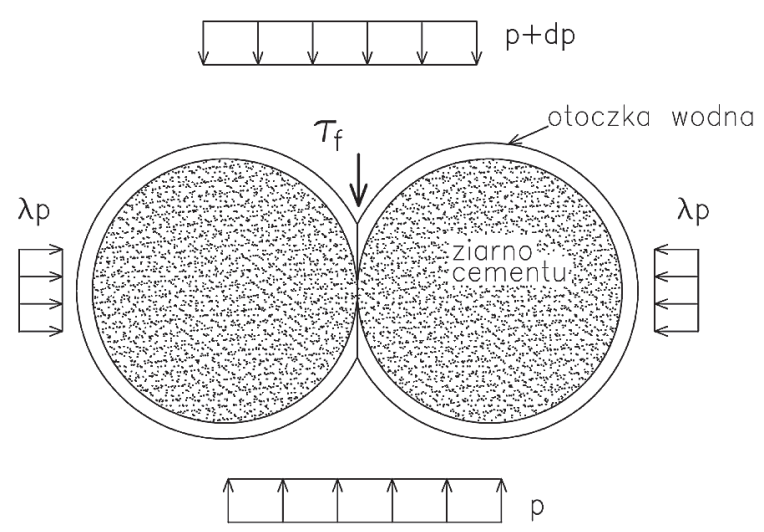

Rys. 2. Mechanizm powstawania oporów tarciowych w mieszance cementowej

Zgodnie z analizą prowadzoną w [7], wielkość oporów tarciowych $\tau_{f}$ zależy od wielkości powierzchni styków cząstek stałych w płaszczyźnie ścinania, wielkości naprężeń normalnych w tej płaszczyźnie oraz kąta tarcia wewnętrznego, według zależności

$$
\tau_{f}=\sigma \cdot m \cdot \operatorname{tg} \varphi
$$

w której $\sigma$ jest naprężeniem normalnym w płaszczyźnie ścinania, $\varphi$ jest kątem tarcia wewnętrznego, $m$ - stosunkiem pola powierzchni styku ziaren do całej powierzchni ścięcia. Zakładając, że naprężenia normalne w płaszczyźnie ścinania są proporcjonalne do wielkości ciśnienia osiowego $p$, ze współczynnikiem rozporu bocznego $\lambda$, można zapisać

$$
\tau_{f}=\lambda \cdot p \cdot m \cdot \operatorname{tg} \varphi
$$

W dalszej części artykułu iloczyn parametrów opisujących stan struktury mieszanki zostanie zastąpiony stałą $k$, stąd

$$
\tau_{f}=k \cdot p
$$

gdzie $k=\lambda \cdot m \cdot \operatorname{tg} \varphi$. 


\section{Przepływ w kanałach cylindrycznych}

Rozkład naprężeń w przekroju kanału kołowego wyznacza się rozpatrując walcowy fragment cieczy w przewodzie tłocznym i ustalając warunki równowagi (Rys. 3)

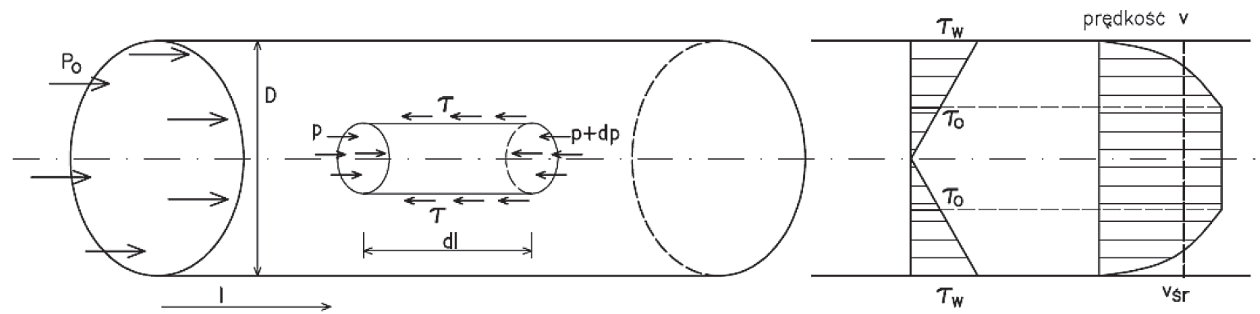

Rys. 3. Schemat wyznaczania rozkładu naprężeń stycznych w kanale tłocznym o przekroju kołowym, rozkład naprężeń stycznych i profil prędkości

Punktem wyjścia do dalszych rozważań jest ogólne równanie przepływu w kanale o przekroju kołowym, pozwalające na znalezienie natężenie przepływu $Q$

$$
Q=\frac{\pi \cdot D^{3}}{8 \tau_{w}^{3}} \int_{0}^{\tau_{w}} f(\tau) \cdot \tau^{2} d \tau,
$$

gdzie $\tau_{w}=-\frac{d p}{d l} \cdot \frac{D}{4}$.

W powyższym równaniu postać zależności funkcyjnej $f(\tau)$ uzależniona jest od przyjętego modelu reologicznego cieczy, pozostałe wielkości pokazano na Rys. 3. Rozwiązanie powyższego równania umożliwia określenie rozkładu ciśnienia łłocznego wzdłuż kanału, a w rezultacie takich istotnych wielkości jak np. zasięg tłoczenia $L$. W pracy [8] przedstawiono sposób przybliżonego rozwiązania równania przepływu dla modelu liniowego ciała plastycznie lepkiego (Binghama) oraz równania końcowe:

- model liniowy bez uwzględniania oporów tarciowych:

ciśnienie wzdłuż kanału $\quad p(l)=P_{0}-\frac{16\left(6 \eta_{p l} \cdot v_{s r}+D \cdot \tau_{0}\right)}{3 D^{2}} \cdot l$

zasięg tłoczenia $\quad L=\frac{3 D P_{0}}{16 \tau_{0}}$

- model liniowy z uwzględnieniem oporów tarciowych:

ciśnienie wzdłuż kanału

$$
\begin{aligned}
& p(l)=-\frac{1}{k}\left(\tau_{0}+\frac{6 \eta_{p l} \cdot v_{s r}}{D}\right)+\left(P_{0}+\frac{1}{k}\left(\tau_{0}+\frac{6 \eta_{p l} \cdot v_{s r}}{D}\right)\right) \cdot e^{-\frac{16 k}{3 D} \cdot l} \\
& \text { zasięg tłoczenia } \\
& L=\frac{3 D}{16 k} \cdot \ln \left(\frac{P_{0} \cdot k}{\tau_{0}}+1\right) .
\end{aligned}
$$

Powyższe wyniki przybliżone uzyskano przyjmując dodatkowe założenie, że wielkość $\frac{\tau_{1}}{\tau_{w}}$ jest mała i w konsekwencji można ją zaniedbać.

W niniejszej pracy powyższe zależności zostały wyprowadzone dla bardziej ogólnego modelu nieliniowo plastycznie lepkiego z uwzględnieniem oporów tarciowych. Szczegółowe rozwiązanie zostało przedstawione poniżej 
Równania konstytutywne są postaci:

$$
\begin{aligned}
& \tau=\tau_{1}+\eta_{p l}\left(\frac{d v}{d r}\right)^{n}, \quad \operatorname{gdy} \tau>\tau_{1}, \\
& \frac{d v}{d r}=0, \quad \text { gdy } \tau \leq \tau_{1} .
\end{aligned}
$$

gdzie w celu uproszczenia zapisów przyjęto $\tau_{1}=\tau_{0}+\tau_{f}$. Funkcja $f(\tau)$ z równania (4.1) jest więc postaci:

$$
f(\tau)=\left\{\begin{array}{cc}
\left(\frac{\tau-\tau_{1}}{\eta_{p l}}\right)^{\frac{1}{n}} & \tau>\tau_{1} \\
0 & \tau \leq \tau_{1} .
\end{array}\right.
$$

Po podstawieniu (4.8) do (4.1) natężenie przepływu jest dane wzorem:

$$
Q=\frac{\pi \cdot D^{3}}{8 \eta_{p l} \frac{1}{n} \cdot \tau_{w}^{3}} \cdot \int_{\tau_{1}}^{\tau_{w}} \tau^{2}\left(\tau-\tau_{1}\right) \frac{1}{n} d \tau
$$

Klasyczne metody rachunku całkowego dają następujący wynik:

$$
\int \tau^{2}\left(\tau-\tau_{1}\right)^{\frac{1}{n}} d \tau=n\left(\tau-\tau_{1}\right)^{\frac{1}{n}}\left(\frac{\tau_{1}^{2}\left(\tau-\tau_{1}\right)}{n+1}+\frac{2 \tau_{1}\left(\tau-\tau_{1}\right)^{2}}{2 n+1}+\frac{\left(\tau-\tau_{1}\right)^{3}}{3 n+1}\right) .
$$

Uwzględniając te rachunki w (4.9) uzyskuje się zależność:

$$
Q=\frac{n \pi D^{3}}{8(3 n+1) \eta_{p l} \frac{1}{n}} \sqrt[n]{\tau_{w}-\tau_{1}} \cdot B\left(\tau_{1} / \tau_{w}\right)
$$

gdzie:

$$
B(x)=1-\frac{1}{(2 n+1)} x-\frac{2 n}{(n+1)(2 n+1)} x^{2}-\frac{2 n^{2}}{(n+1)(2 n+1)} x^{3} .
$$

Przyjmując założenie, że wielkość $\frac{\tau_{1}}{\tau_{w}}$ jest wielkością małą otrzymuje się w konsekwencji, że $B \approx 1$, a stąd przybliżoną wartość natężenia przepływu:

$$
Q=\frac{n \pi D^{3}}{8(3 n+1) \eta_{p l} \frac{1}{n}} \sqrt[n]{\tau_{w}-\tau_{1}}
$$

Z równania ciągłości przepływu wynika, że $Q=v_{s r} \frac{\pi D^{2}}{4}$. Łącząc dwa powyższe wzory można otrzymać związek:

$$
\sqrt[n]{\tau_{w}-\tau_{1}}=\frac{2(3 n+1) v_{s r} \eta_{p l}^{\frac{1}{n}}}{n D}
$$


skąd, po uwzględnieniu wzorów na $\tau_{1}$ i $\tau_{w}$, można uzyskać równanie

$$
\frac{D}{4} \cdot \frac{d p}{d l}+k p=-A
$$

gdzie: $A=\tau_{0}+\frac{{v_{s} r}^{n} 2^{n}(3 n+1)^{n} \eta_{p l}}{D^{n} n^{n}}$.

Rozwiązaniem ogólnym otrzymanego równania różniczkowego z warunkiem początkowym $p(0)=P_{0}$ jest funkcja

$$
p(l)=-\frac{A}{k}+\left(P_{0}+\frac{A}{k}\right) \cdot e^{-\frac{4 k}{D} \cdot l}
$$

Po uwzględnieniu warunku brzegowego $p(L)=0$ oraz $v_{s}=0 \mathrm{w}$ chwili zastopowania przepływu obliczamy zasięg tłoczenia:

$$
L=\frac{D}{4 k} \cdot \ln \left(1+\frac{P_{0} \cdot k}{\tau_{0}}\right) .
$$

W wyniku przyjęcia określonego modelu reologicznego uzyskuje się różne postacie równań przepływu, a co za tym idzie, pojawiają się różnice w przewidywanych wynikach procesu przepływu. Jak wynika z otrzymanych wzorów, zasięg przepływu $L$ zależy tylko od jednego z podstawowych parametrów reologicznych, tj. od granicy ścinania $\tau_{0}$. Taka sytuacja ma miejsce w każdym $\mathrm{z}$ analizowanych przypadków, co potwierdza spostrzeżenia zawarte w pracy [9].

\section{Dyskusja rozwiązania równania przepływu}

W omówionych w poprzednich rozdziałach modelach, natężenie przepływu wyrażone jest w skomplikowany sposób, co nie pozwala na łatwe wyznaczenie ciśnienia tłoczenia dyspersji cementowej. Przyjmowano więc dodatkowe założenia upraszczające równania modelowe, dzięki czemu uzyskane zostały wyniki dotyczące samego ciśnienia (wzory (4.2), (4.4), (4.15)), jak i zasięgu tłoczenia (wzory (4.3), (4.5), (4.16)).

Warto jednak zauważyć, że z samego założenia upraszczającego równania modelowe można wyprowadzić pewne wnioski dotyczące ciśnienia i zasięgu tłoczenia zawiesiny cementowej.

Przyjęcie założenia, że wielkość $\frac{\tau_{1}}{\tau_{w}}$ jest mała prowadzi do prostego równania różniczkowego. Kładąc $\frac{\tau_{1}}{\tau_{w}}=\varepsilon$ oraz stosując wzory na $\tau_{1}$ i $\tau_{w}$ można otrzymać równanie

$$
\frac{\varepsilon D}{4} \cdot \frac{d p}{d l}+k p=-\tau_{0}
$$

Łatwo zaobserwować, że równanie (5.1) ma podobny charakter jak równanie (4.14). Rozwiązaniem tego równania z warunkiem początkowym $p(0)=P_{0}$ jest

$$
p(l)=-\frac{\tau_{0}}{k}+\left(P_{0}+\frac{\tau_{0}}{k}\right) \cdot e^{-\frac{4 k}{\varepsilon D} \cdot l} .
$$


Widać więc, że rozważanie przybliżeń dla konkretnych modeli przepływu dyspersji cementowej prowadzi do „uszczegółowienia” funkcji będącej rozwiązaniem równania przepływu, tj. uwzględnienia innych parametrów występujących w modelu $\left(v_{s r}, \eta_{p l}\right)$.

Ze wzoru (5.2) można uzyskać wielkość zasięgu tłoczenia. Mianowicie, z warunku $p(L)=0$ wynika, że

$$
L=\frac{\varepsilon D}{4 k} \cdot \ln \left(1+\frac{P_{0} \cdot k}{\tau_{0}}\right) .
$$

Należy zaznaczyć, że wyniki uzyskane w tym rozdziale należy traktować jako bardzo zgrubne oszacowania, jednakże pokrywające się swą postacią z wynikami omawianymi w rozdziale 4 .

\section{Analiza liczbowa równań przepływu}

Porównanie wyników obliczeń uzyskanych na podstawie przedstawionych równań przepływu przeprowadzono przyjmując następujące wielkości:

- parametry technologiczne: $P_{0}=0,4 \mathrm{MPa}, D=2,0 \mathrm{~mm}, v_{\dot{s} r}=0,05 \mathrm{~m} / \mathrm{s}$;

- parametry reologiczne: $\quad \tau_{0}=13,0 \mathrm{~Pa}, \eta_{p l}=0,15 \mathrm{~Pa} \cdot \mathrm{s}, n=0,5 \mathrm{MPa}$;

- parametry tarciowe: $\quad \lambda=0,94, \operatorname{tg} \varphi=0,03, m=0,043$.

Poszczególne dane do obliczeń zostały określone na podstawie własnych badań doświadczalnych (parametry reologiczne) danych literaturowych (tarciowe) oraz praktycznych zastosowań iniekcji ciśnieniowej (parametry technologiczne).

Zmiana ciśnienia tłocznego $p$ na długości kanału $l$ oraz zasięg tłoczenia $L$, obliczone na podstawie trzech przedstawionych w rozdziale 4 równań przepływu, zostały przedstawione na Rys. 4.

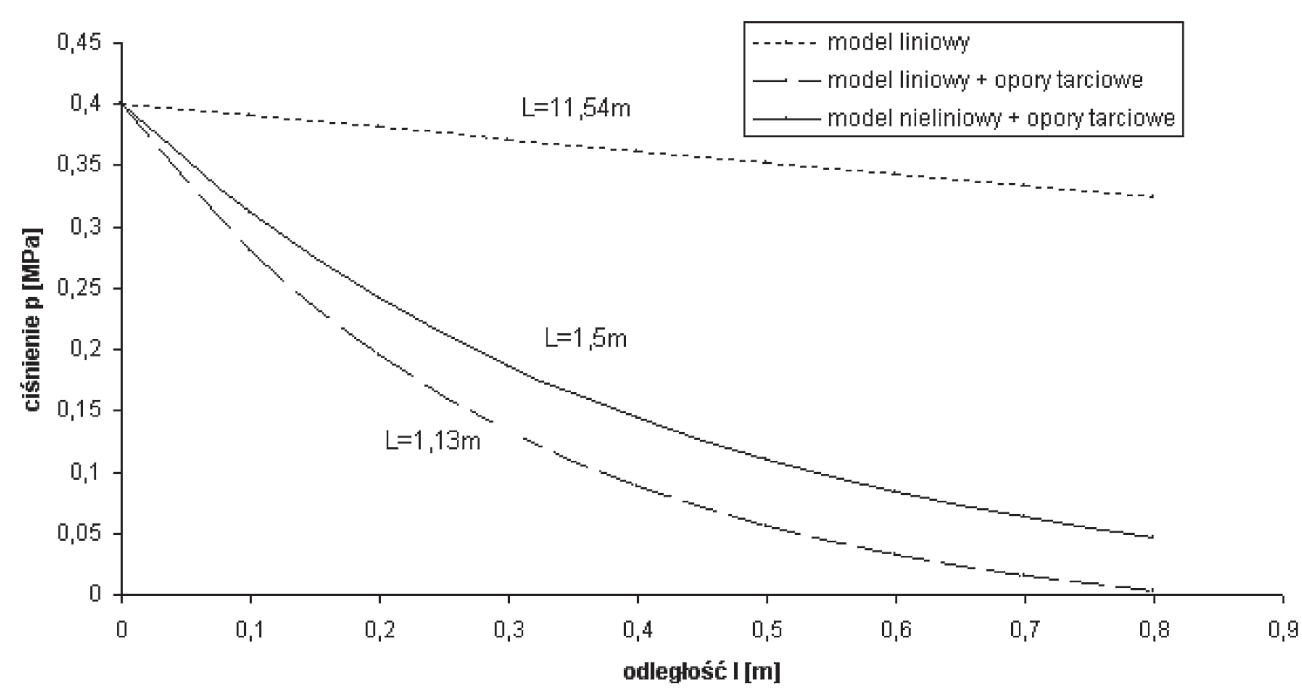

Rys. 4. Porównanie wyników obliczeń zmian ciśnienia tłocznego $p$ oraz zasięgu tłoczenia $L$, dla trzech modeli reologicznych 
Nieuwzględnianie oporów tarciowych w klasycznym modelu Binghama skutkuje uzyskaniem nadmiernie dużych - w stosunku do obserwowanych w praktyce - wartości zasięgu tłoczenia. Bliższe rzeczywistym możliwościom dyspersji cementowych są wyniki obliczeń uzyskane na podstawie modeli, które uwzględniają tarciowe opory przepływu. Występowanie mniejszych oporów przepływu przewiduje model nieliniowy, uwzględniający obserwowane w rzeczywistości zjawisko tzw. rozrzedzania ścinaniem, a więc zmniejszanie się wartości lepkości w trakcie płynięcia. Efekt ten ma kilka przyczyn: po pierwsze przy ścinaniu zachodzi efekt uwalniania się wody błonkowej, zwiększając ilość wody wolnej, po drugie następuje orientacja wzdłuż linii przepływu początkowo bezładnie ułożonych cząstek o wydłużonym kształcie. Mniejsze opory przepływu w przypadku modelu nieliniowego skutkują zwiększeniem o 1/3 zasięgu przepływu, co zilustrowano na Rys. 5.

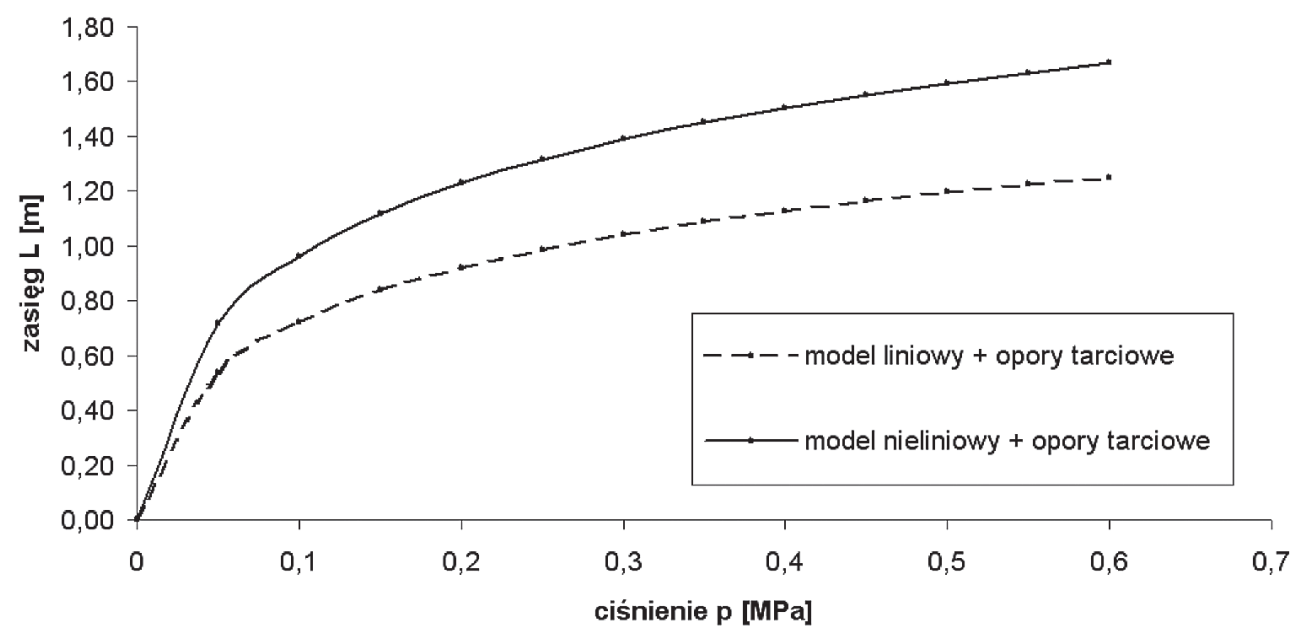

Rys. 5. Wyniki obliczeń zasięgu tłoczenia $L$ wg równań (4.5) i (4.16)

\section{Podsumowanie}

Klasyczny model ciała Binghama nie oddaje w sposób dokładny rzeczywistego zachowania się dyspersji cementowych, przewidując mało realne w praktyce długości przepływu. Posługiwanie się takim modelem reologicznym prowadziłoby do zbyt optymistycznych przewidywań i w konsekwencji różnorakich błędów w praktycznych realizacjach. Modele dyspersji cementowej, uwzględniające składnik oporów tarciowych na stykach ziaren cząstek stałych, pełniej opisują zjawiska zachodzące w trakcie jej przepływu ciśnieniowego. $\mathrm{Z}$ kolei uwzględnienie nieliniowego charakteru płynięcia przedstawione $\mathrm{w}$ niniejszym artykule wiąże się z nieco bardziej skomplikowanymi przekształceniami, prowadzi jednak do uzyskania zbliżonych równań wynikowych jak w przypadku modelu liniowego. Powstające różnice są natury ilościowej i są ogólnie zgodne z przewidywaniami.

Otrzymane równania przepływu wiążą parametry reologiczne, geometryczne i technologiczne, pozwalając na rozpoznanie zależności pomiędzy nimi i bardziej świadome projektowanie procesu tłoczenia dyspersji cementowych. 


\title{
Literatura
}

[1] Happel J. Viscous flow in multiparticle systems: Slow motion of fluids relative to beds of spherical particles. AIChE Journal 4. No 21958.

[2] Osswald T., Hernandez-Ortiz J.P. Polymer Processing. Modeling and Simulation, Hanser Pub. Munich 2006.

[3] Chen Z., Huan G., Ma Y. Computational Methods for Multiphase Flow in porous Media. SIAM. Philadelphia 2006.

[4] Chin W.C. Computational Rheology for Pipeline and Annular Flow. Gulf Professional Publishing. Boston 2001.

[5] Grzeszczyk S. Reologia zawiesin cementowych. PAN 1999.

[6] Mierzwa J. Właściwości reologiczne zaczynów cementowych stosowanych w wybranych procesach technologicznych budownictwa. Monografia. Politechnika Krakowska 1988.

[7] Szwabowski J. Reologia mieszanek na spoiwach cementowych. Wydawnictwo Politechniki Śląskiej. Gliwice 1999.

[8] Szerafin J. Dyspersje cementowe w procesie iniekcyjnej naprawy defektów struktury betonu. Monografia. Politechnika Lubelska 2011.

[9] Hansson P. Filtration stability of cementitious injection grouts witk low w/c-ratio. Concrete Repair, Rehabilitation and Protection. London 1996.

\section{Flow modeling of the cement dispersion as non-linear viscoplastic fluid}

\author{
Jerzy Szerafin ${ }^{1}$, Pawel Zaprawa² \\ ${ }^{1}$ Faculty of Civil Engineering and Architecture, Lublin University of Technology, \\ e-mail: j.szerafin@pollub.pl \\ ${ }^{2}$ Faculty of Mechanical Engineering, Lublin University of Technology, \\ e-mail:p.zaprawa@pollub.pl
}

The analitycal solution for pipeline and annular flow of the cement dispersion for non-linear viscoplastic model of the fluid, compared with another reological models were presented in the paper. The calculations of the pressure gradient and injection range shows that it is necessary to take into account the friction factor in the theoretical analysis of the cement grout flow.

Keywords: cement dispersion, flow, modelling. 
